\title{
AC 2009-1848: BLENDING ONLINE LEARNING WITH A TRADITIONAL COURSE
}

\section{Christi Patton Luks, University of Tulsa}

Dr. Patton earned a B.S. in Chemical Engineering from Texas A\&M University, a M.S. in Applied Mathematics from The University of Tulsa and a Ph.D. in Chemical Engineering from The University of Tulsa. Currently she is Applied Associate Professor of Chemical Engineering at the University of Tulsa. She directs many interdisciplinary design projects through the Chemical Engineering department and Engineers Without Borders. 


\title{
Blending Online Learning with a Traditional Course
}

\author{
Christi L. Patton \\ The University of Tulsa
}

\begin{abstract}
As class sizes in a chemical engineering problem solving class outgrew the available rooms and one teacher's ability to maintain a personal relationship with students and to safely manage hands-on design projects, a new class management philosophy was needed. Two credit-hours of this three-credit-hour course were conducted electronically while students met in a classroom in a group of 10 - 12 students for the remaining one-hour-per-week lecture. Blackboard Learning System - Vista Enterprise was used to post video lectures, manage quizzes and homework assignments.
\end{abstract}

This paper looks at the effectiveness of this blending of online learning with traditional lecture and hands-on activities after two years of implantation. In particular, the paper will examine the details of course management and highlight what did and did not work in terms of student learning and student retention. Advantages and disadvantages to both the instructor and the student will be presented.

Finally, this paper will examine how this new approach created the opportunity to add an independent study variation on this course. This online-only course has proven beneficial for several students who transferred into the chemical engineering program after the first year and requires very little extra workload for faculty.

\section{Background}

Degrees conferred from chemical engineering programs across the U.S. declined $34 \%$ between 1997 and $2006^{1}$ and The University of Tulsa (TU) has mirrored this trend. This same period of time saw significant changes in the technology infrastructure at TU in the College of Engineering and Natural Sciences. Every classroom was equipped with a computer console and display for instruction. All engineering departments established computer laboratories for their students in addition to the numerous facilities available to all students. WiFi was installed campus-wide. Two instructional laboratories were created with computers for 20 or 30 students.

In 2007 and 2008, the public watched the price for a barrel of oil rise to unprecedented levels. Salaries for engineers prepared to work in the petroleum industry sky-rocketed. Even as the economy foundered and the price of oil plummeted in the fall of 2008 major oil companies continued to make offers to graduating seniors. At TU, the enrollment of new students in petroleum-related fields is on the rise. The chemical engineering department has benefitted from this, with enrollment of new students in the ChE program increasing nearly $70 \%$ from 2006 to 2008. While increasing enrollments are good for the university, they have also created a host of new problems relating to space and equipment limitations. Classrooms are at capacity during the most popular time slots. The computer instructional laboratories can no longer accommodate a 
full class. Instructors, accustomed to small, intimate class sizes where they could learn every student's name within the first week, are now facing larger groups where students can easily slip into anonymity.

In the past decade, teachers began incorporating more active-learning activities and hands-on design projects. The freshman-level courses, in particular, benefitted from this change in philosophy. Now, it should be noted that, at TU, freshmen select a major as they enter the university. The introductory classes are discipline-specific and each department teaches their freshmen. In chemical engineering, the freshman year has a two-course sequence. ChE 1002 is a two-hour course taught in the fall semester to introduce students to the career while ensuring that they have the necessary background skills (unit conversions, graphing, etc.). ChE 1013 is a three-hour course taught in the spring semester. The students learn to program with Excel and VBA and use these skills in a design project and competition. The design project varies from year to year but always involves students designing and running their own experiments to control a chemical reaction for a defined purpose. This is potentially chaotic, but small class sizes enable the professor to manage this in a safe and beneficial manner. In 2008, the enrollment in ChE 1013 exceeded the available space in the largest computer classroom and the instructor's ability to safely manage the design project and experimentation. There were no available teachers to open up a new section. Therefore, a new class management philosophy was required.

\section{Restructuring ChE 1013}

The ChE 1013 course was reorganized for Spring 2008 to allow for smaller class sizes without requiring a significant increase in teaching load. The course was divided into two distinct components: one hour per week of classroom instruction and two hours per week of self-paced electronic instruction. The students were divided into three groups of up to 12 which each met once per week for 50 minutes during one of the original designated class times. This time was used for the design component of the class and for student presentations. The remaining twothirds of the course were conducted online through Blackboard Learning System - Vista Enterprise (www.blackboard.com). This portion of the course focused on programming with Excel and with VBA. These programming skills were used in the design project and so there were opportunities to discuss these with these smaller groups of students. This paper will focus on the self-paced portion of the course.

All TU students have access to Vista. Most teachers use this as a repository of handouts and course supplements or to post grades throughout the semester. It has many additional capabilities and is designed to manage entire online courses or as a supplement to more traditional courses. For ChE 1013, the instructor created 26 modules incorporating (1) videotaped lessons, (2) links to supplemental online materials, (3) online quizzes, and (4) homework assignment. Each lesson had a due date. After the due date student could still complete the work with a two-point penalty each day after the due date.

The videotaped lessons were created using a screen recording software by TechSmith: Camtasia Studios (www.techsmith.com/camtasia.asp). When used with a microphone, the instructor can talk the students through what they are doing on the computer while they visually follow the actions. Input from a video camera, background music, title screens, and more can easily be 
added. Files may be produced in one or more format. Experimenting with Camtasia in a previous course, students at TU seemed to prefer the flash files or podcasts. For this course, the videos were produced as Flash SWF files. Some lessons were recorded at the university while others were recorded from home. Since the professor did not need to wait for students to catch up or answer any questions, the lectures that would normally take 50 minutes in class were reduced to $20-30$ minutes on video without reducing the content. When students needed to catch up, they were able to pause the video.

Each lesson had an electronic quiz and an assignment that was submitted electronically. These were mostly multiple choice, matching, or true-false questions. Some open-ended calculations and short answer questions were used. There were multiple versions of each quiz. All quizzes were set up so that they could be graded automatically. The assignments were submitted through Vista. Students occasionally had hand-written papers to turn in. A scanner was available for their use in one of the student computer labs. Assignments were graded by the professor. Since it was possible that students could have had a proxy do the online work for them, the students were held individually accountable with an in-class midterm exam and in-class final exam over the electronic material.

\section{Student Reactions}

The comment section of university course assessments indicated that students were very positive about the new format of the course. Since they still had class time with the instructor, they did not feel anonymous. It was very important to the students that they had a relationship with the instructor. Occasionally there were technical problems, but students reported them and they were corrected that day. Several students reported that they had saved copies of all videos and a few asked for a DVD of the video lessons for them to review as they need them later.

Students enjoyed the advantage of going through the lessons at their leisure. Since their background and familiarity with Excel varied greatly, some found that they could go through most lessons without pausing. On more challenging lessons they could pause or repeat portions of the videotape. Most students did the lessons from home. Some did not have reliable internet access at home and so completed the lessons on campus with university computers. They could bring their own headphones and listen to the audio without creating a disturbance.

There were disadvantages for the students. The biggest difficulty for them was because they typically did the lessons on their own late at night. When they had questions, they could post them to the class through a discussion board, email them to the instructor, or wait until the next day's office hours or next class session. None of the choices provided immediate feedback.

A significant number of students (23\%) procrastinated until "last call" messages went out. Several of this group watched the video lessons in a timely manner, but did not take quizzes or turn in assignments until they faced a firm deadline. A penalty of two points per day was not adequate to motivate this group of students. Surprisingly, the majority of this group liked the freedom to do it their own way even though their grades suffered. 
One student commented that they greatly preferred the online lessons for the Excel portion of the course, but that they would have benefitted from traditional lectures when we moved to the VBA lessons. Their thought was that it would "encourage questions and help the students understand the material more thoroughly."

\section{Instructor's Reaction}

From the instructor's point of view, this was a very positive experience. There was no statistically meaningful change in student performance on the programming portion of the course. Meeting with small groups, even though there were fewer contact hours per student, provided a tremendous opportunity for interacting with the students. Managing the design project with fewer students was decidedly less stressful and a safer, calmer work environment was maintained.

Creating material for the electronic portion of the course was more time-consuming than preparing similar material for a traditional course. This was partly due to the learning curve with using these packages. However, it did take longer to prepare lectures even after the instructor became comfortable with the materials. Preparation of a lecture outline did not change, and delivery of the lesson was shorter. Unfortunately, after recording the lecture (approximately 25 minutes) the video and audio must be interwoven and saved (approximately 3 minutes during which the computer is occupied and not easily used for other activities), the video is rendered into an appropriate form for playback (approximately 15 minutes but running in the background), and finally it is uploaded to the website. Uploading the videos from campus was quick (approximately 2 minutes) but from home on an icy day this could take up to an hour! The time to create an electronic assignment on Vista was typically 5 minutes. The time to create questions and quizzes was typically 30 minutes. Therefore, the 50 minute lecture required at least 20 extra minutes to prepare under ideal conditions.

It was quickly determined that editing the videos to a more polished final product was not time well-spent. Occasionally students would make comments when they saw me about the phone working or the dog barking during a lesson. That reassured me that they were watching the lessons and gave me an opportunity to chat casually with them about the experience. For those who expressed opinions, the casualness of the unedited videos "felt" more like being in class.

One significant benefit of having these lessons pre-assembled, is that they can be re-used. This has allowed transfer students needing to learn the material prior to their enrollment in the Fall of 2008 to work on these lessons as an independent study with very little additional effort from the instructor.

The instructor, like the students, enjoyed not being committed to a specific time slot for lecture. Lectures could be prepared at home at odd hours and without regard for proper attire.

Sometimes it was difficult to feel motivated to provide an energetic lecture without an audience.

Modifications for 2009 
For 2009 several changes were made in response to comments made from the previous group. When possible, video lessons were re-used. The university changed to a newer version of Microsoft Office for the Fall 2008 term and so 11 video lessons on Excel were new for Spring 2009. For students using the older version of the software, the old video lessons were available.

In response to the student that preferred in-class lectures on the difficult material, the instructor now offers a special session each week for anyone that is interested. The published format of the session is a brief re-cap of the two lessons for the week with time for questions and discussion. In the early part of the semester while the material is easy, attendance has been sparse. As the difficulty increases, it is expected that attendance will increase.

A new structure for encouraging students to complete their work in a timely manner is now in place. First, the penalty for late work has been doubled to 4 points per day. A grid of the available points for each assignment on each day was included in the syllabus. Students have also been warned that there is a formal policy to pester them if they fall behind. When students fail to submit an assignment within a few days of the due date they receive a reminder email from the instructor. If multiple assignments are outstanding the student receives a summons to visit with the instructor. The first week students were asked to designate a classmate that will be their "encourager". If the procrastination persists, this classmate is told that their friend needs encouragement to catch up. No additional guidelines are given to the students. This method was used informally with two students and Spring 2008 and formally with all students for Spring 2009. It appears to be more fun for everyone and more effective than being reminded by the instructor.

\section{Application to Other Courses}

The online lessons are now being blended into many other courses within the department. Several upperclassmen and graduate students have requested access to the video lessons so that they can improve their computer skills. Students have also asked other professors to make recordings of specific lectures that they would like to be able to view again. Faculty members have found that video lessons can be used to make up lectures when they must be away from campus. During a recent period of icy weather, students had the option of attending class and taking the weekly quiz with the group or watching an online version of the lecture and taking an electronic variation of the quiz. Many lectures, especially those on the use of computer tools, are now being recorded so that students can review them as they use the tools. Students and faculty alike continue to find new and effective ways of utilizing methods that were initially reserved for distance learning in a traditional course.

\section{Bibliography}

1. U.S. Department of Education, National Center for Education Statistics, Higher Education General Information Survey (HEGIS), "Degrees and Other Formal Awards Conferred" surveys, 1970 - 71 through 1985-86; and 1986-87 through 2005-06 Integrated Postsecondary Education Data Systems, "Completions Survey" (IPEDS-C:87-99), and Fall 2000 through Fall 2006. http://nces.ed.gov/programs/digest/2007menu_tables.asp. Table prepared June 2007. 